\title{
Student Perceptions \\ Of Password Security And Maintenance
}

Cynthia L. Knott, Marymount University, USA

G. Steube, Marymount University, USA

\begin{abstract}
Increasing concerns about security and privacy have raised the bar for interest in ways to protect information. Although newer approaches include face recognition, the use of passwords is commonly used today as the best approach for protecting data. Web sites, software programs, financial institutions universities, and many commercial stores are requiring that a password include the following attributes: consist of a fixed number of characters, include numbers and letters, special characters and lower and upper case letters. In addition, repetition of a password is not allowed, i.e. the updated password must be original to the user. These circumstances are just a few of the requirements that have made generating a password somewhat of a challenge. Many institutions also require changing a password on a regular schedule. The growth of the use of password coupled with the frequency of changing these codes have made the creation and use of passwords a challenging necessity.
\end{abstract}

This paper explores how students view and use password protection. One of the questions addressed in this research is: Do student attitudes toward password protection impact how passwords are used? Another inquiry discussed in this paper is perception of the importance of the use of passwords. Interest in using an automated tool to facilitate use of password protection is also explored. Evidence connecting the use of passwords and the habits developed by undergraduates in protecting their information are also explored in this paper. Some of the questions addressed in this research include the following:

- How many web sites do you visit that require a password?

- Given the following classifications: personal banking, social networking, shopping, and gaming, how many websites of each type do you use that require passwords?

- How do you view the importance of password security?

- How many passwords do you use?

- How often do you change your password(s) voluntarily?

- How often do you change your password(s) because you are required to?

- Do you find it challenging to change your passwords, given many sites requirements, to include a capital letter, symbol or other character?

- $\quad$ Are you familiar with any software that aids in creation and/or saving of your personal passwords? If so, which software?

- Would you be interested in such a tool, if you aren't familiar with one?

- Of the following devices: desktop, iPad, laptop, and cell phone, how would you rate the importance of securing them with password protection?

The findings of the survey help to understand the perspective of today's students and how to address the critical need to secure their passwords. The consequence of misapplying a password can lead to frustration, loss of information, and delays in accessing data. The practice of employing an automated password tool is seen as a solution to the complexities of creating and applying passwords.

This research contributes to understanding some of the attitudes and habits of students in their use of passwords. Approximately $94 \%$ of the respondents to the survey felt that password protection was important. The perception of the degree of trouble of changing password was almost evenly divided between a high level of difficult and a low level of difficulty among the students surveyed. The majority of students in the study (57\%) are interested in learning about a software tool to automate password management. 
In terms of the relationships between the perceptions and the behaviors reported in the survey, it was found that there is a significant relationship between the number of sites requiring passwords and the use of passwords. There was also a significant relationship between the difficulty in changing passwords and interest in an automated tool.

Keywords: Password Security; Password Privacy; Password Maintenance; Student Perceptions of Password Security \& Maintenance

\section{INTRODUCTION}

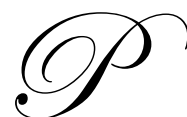

asswords may be words or strings of characters that are used to verify identity to gain access to a resource. Passwords have been used in ancient times especially as guard words for sentries and other military applications (About.com, 2011). In modern times, passwords have been associated with computers since their early days and used to verify identity for logging into the system (Morris \& Thompson, 1979). Remembering a few passwords is generally not a difficult task; however, as more computers, networks and web sites are used the more challenging the effort. In addition to the number of devices expanding that require passwords the range of uses has also increase the need for more passwords. Ideally every password should be unique, but it may not be possible to reduce the number of passwords to be remembered without decreasing security (The JNT Association, 2007). Given the increase in the demands for passwords, how do users perceive the challenges and address the need for securing their identities through passwords? To begin to answer this question, the research in this paper examines the perceptions of undergraduate students about their use of passwords.

\section{PROCEDURE}

A survey was administered to undergraduate students at a small private college on the east coast. A copy of the survey questions is available in Appendix A. The purpose of the research was to gather information about the use of passwords by students and their attitudes about securing information through passwords. The frequency of password usage and the types of applications that require passwords were also investigated. The number of passwords used along with their frequency of changing the password was collected in this survey. Student perception about the importance of the use of password protection for securing a variety of electronic devices including desktop computers, iPads, laptops, cell phones and e-readers was captured in this assessment.

\section{POPULATION}

The target population for this research is undergraduate students. This research sampled students in three undergraduate quantitative courses. The majority of students in the sample were juniors who were majoring in business; the sample size was 49. It is believed that the results of the sampling process used are generalizable to the target population of undergraduate students and reflect the perception and practice of password protection.

\section{RESEARCH QUESTIONS}

This paper examines the perceptions about password protection as well as the practice of password protection. Questions explored surrounding the perception of password protection includes: (1) How do students view the importance of password protection? (2) How difficult is it to change passwords? (3) What is the interest in an automated tool to manage passwords? Questions that address the practice of password protection by students are: (1) How many web sites and what types of sites do students visit that require passwords? (2) How many passwords do students use? (3) Do students change passwords more frequently on voluntarily or an involuntary basis? The answers to these questions are addressed in the survey and consequently they are summarized using descriptive statistics.

This research also investigates the relationship between certain perceptions and their connection to practice. These questions include: (1) Does the perception of password protection importance impact password usage? (2) Does the perception of importance affect interest in an automated software management tool? (3) Does the difficultly in changing passwords impact the interest in an automated tool? (4) Do the number of sites visited increase the usage of passwords? 
The four questions addressing the relationships between perception and practice were analyzed using contingency tables with a chi-square with a phi coefficient to test the associations. Phi is a chi-square based measure of association; the chi-square coefficient depends on the strength of the relationship and sample size. Since phi has a known sampling distribution it is possible to compute its standard error and significance (Howell, 2002). For this analysis the strength of the association will be assessed through a rule of thumb which provides a range of values for Phi and verbal assessment. Strong negative and strong positive associations are represented by Phi values between 1.0 to -.7 and .7 to 1.0 , respectively. Weak negative and positive associations are between -.7 to -.3 and .3 to .7 , respectively. Values of Phi indicating little or no association are between -.3 to .3 (Simon, 2005).

\section{SURVEY INSTRUMENT}

Table 1 identifies the sources of the analysis from the survey questions. In this table each question and a brief caption is presented to identify the relationships that were examined. Several variables were recoded to develop categorical groups for the analysis; these groups and their labels are in Table 2. Tables 1 and 2 connect the questions in the survey to the variables that will be examined in this research. The results of this analysis are presented in the following section.

Table 1

Questions and Captions

\begin{tabular}{ll}
\hline Question & Caption \\
\hline 1 & Web Sites Requiring Passwords \\
2 a & Password for Banking \\
2 b & Passwords for Social Networks \\
2 c & Passwords for Shopping \\
2 d & Passwords for Gaming \\
3 & Importance of Passwords \\
4 & Passwords Used \\
5 & Voluntarily Change Passwords \\
6 & Involuntarily Change Passwords \\
7 & Difficulty in Changing Passwords \\
8 & Familiar with Password Software \\
9 & Name of Password Software \\
10 & Interest in Password Software \\
11 & Password Importance: Desktops Computers \\
12 & Password Importance: iPad/Tablet \\
13 & Password Importance: Laptop/Notebook \\
14 & Password Importance: Cell Phone \\
15 & Password Importance: E-reader \\
\hline
\end{tabular}

Table 2

Categorical Groups

\begin{tabular}{|c|c|c|}
\hline Question & Response & Category Name (Value) \\
\hline Question 1 & $\begin{array}{l}\text { ny web sites do you visit t } \\
\text { a) } 0-5 \\
\text { b) } 6-10 \\
\text { c) } 11-15 \\
\text { d) more than } 15\end{array}$ & $\begin{array}{l}\text { Low (1) } \\
\text { Medium (2) } \\
\text { High (3) } \\
\text { Very High (4) }\end{array}$ \\
\hline Question 3 & $\begin{array}{l}\text { aportance of password sec } \\
\text { a. Extremely Important } \\
\text { b. Somewhat Important } \\
\text { c. Not that Important } \\
\text { d. Not Important at all }\end{array}$ & $\begin{array}{l}\text { High (1) } \\
\text { High (1) } \\
\text { Low (0) } \\
\text { Low (0) }\end{array}$ \\
\hline
\end{tabular}


Table 2: Continued

Question 4: Approximately how many passwords do you use?
a. $1-2$
Low (1)
b. $3-5$
Medium (2)
c. $6-10$
High (3)
d. $11-15$
Very High (4)

Question 7: How difficult do you find it to change your passwords, given many sites requirements to include a capital letter, symbol etc...?
a. Extremely Difficult
Difficult (1)
b. Somewhat Difficult
Difficult (1)
c. Difficult
d. Not that Difficult
Difficult (1)
e. Not Difficult at all
Not Difficult (0)
Not Difficult (0)

Question 10: Would you be interested in such a tool, if you aren't familiar with one?

$\mathrm{Y}$

Interested (1)

$\mathrm{N}$

Not Interested (0)

\section{DISCUSSION OF PERCEPTIONS}

Descriptive statistics are provided for the results of the perception questionnaire before examining the relationship between perception and practice. The first question examined the number of web sites that require a password. Table 3 presents the distribution of responses to question 1. Approximately $78 \%$ of the students in the sample visit web sites that require 10 or fewer passwords.

Table 3

Question 1: Approximately how many web sites do you visit that require a password?

\begin{tabular}{lcccc}
\hline & Frequency & Percent & Valid Percent & Cumulative Percent \\
\hline $0-5$ & 20 & 40.8 & 40.8 & 40.8 \\
$6-10$ & 19 & 38.8 & 38.8 & 79.6 \\
$11-15$ & 3 & 6.1 & 6.1 & 85.7 \\
$15+$ & 7 & 14.3 & 14.3 & 100.0 \\
Total & 49 & 100.0 & 100.0 & \\
\hline
\end{tabular}

The categories of web sites that require passwords are displayed in Table 4 . Approximately $57 \%$ visit at least one banking site, over $60 \%$ surf to at least two social networking sites, $32 \%$ enter at least 2 shopping sites, and about $77 \%$ do not use any gaming sites that require a password.

Table 4

Question 2: Approximately how many web sites of each type do you use that require passwords? Web Sites Visited by Banking Category

\begin{tabular}{llcccc}
\hline & Frequency & Percent & Valid Percent & Cumulative Percent \\
\hline & 0 & 2 & 4.1 & 4.2 & 4.2 \\
& 1 & 28 & 57.1 & 58.3 & 62.5 \\
& 2 & 10 & 20.4 & 20.8 & 83.3 \\
& 3 & 2 & 4.1 & 4.2 & 87.5 \\
& 4 & 6 & 12.2 & 12.5 & 100.0 \\
Missing & Total & 48 & 98.0 & 100.0 & \\
Total & System & 1 & 2.0 & & \\
\hline
\end{tabular}


Table 4 (Continued)

Web Sites Visited by Social Networking Category

\begin{tabular}{llcccc}
\hline & Frequency & Percent & Valid Percent & Cumulative Percent \\
\hline & 0 & 2 & 4.1 & 4.2 & 4.2 \\
& 1 & 18 & 36.7 & 37.5 & 41.7 \\
& 2 & 14 & 28.6 & 29.2 & 70.8 \\
& 3 & 7 & 14.3 & 14.6 & 85.4 \\
& 4 & 5 & 10.2 & 10.4 & 95.8 \\
Missing & 5 & 2 & 4.1 & 4.2 & 100.0 \\
Total & Total & 48 & 98.0 & 100.0 & \\
\hline
\end{tabular}

Web Sites Visited by Shopping Category

\begin{tabular}{|c|c|c|c|c|c|}
\hline & & Frequency & Percent & Valid Percent & Cumulative Percent \\
\hline & 0 & 14 & 28.6 & 29.2 & 29.2 \\
\hline & 1 & 10 & 20.4 & 20.8 & 50.0 \\
\hline & 2 & 6 & 12.2 & 12.5 & 62.5 \\
\hline & 3 & 3 & 6.1 & 6.3 & 68.8 \\
\hline & 4 & 4 & 8.2 & 8.3 & 77.1 \\
\hline & 5 & 6 & 12.2 & 12.5 & 89.6 \\
\hline & 6 & 2 & 4.1 & 4.2 & 93.8 \\
\hline & 7 & 1 & 2.0 & 2.1 & 95.8 \\
\hline & 8 & 1 & 2.0 & 2.1 & 97.9 \\
\hline & 30 & 1 & 2.0 & 2.1 & 100.0 \\
\hline & Total & 48 & 98.0 & 100.0 & \\
\hline Missing & System & 1 & 2.0 & & \\
\hline Total & & 49 & 100.0 & & \\
\hline \multicolumn{6}{|c|}{ Web Sites Visited by Gaming Category } \\
\hline & & Frequency & Percent & Valid Percent & Cumulative Percent \\
\hline & 0 & 38 & 77.6 & 79.2 & 79.2 \\
\hline & 1 & 2 & 4.1 & 4.2 & 83.3 \\
\hline & 2 & 3 & 6.1 & 6.3 & 89.6 \\
\hline & 4 & 1 & 2.0 & 2.1 & 91.7 \\
\hline & 5 & 1 & 2.0 & 2.1 & 93.8 \\
\hline & 6 & 1 & 2.0 & 2.1 & 95.8 \\
\hline & 9 & 1 & 2.0 & 2.1 & 97.9 \\
\hline & 12 & 1 & 2.0 & 2.1 & 100.0 \\
\hline & Total & 48 & 98.0 & 100.0 & \\
\hline Missing & System & 1 & 2.0 & & \\
\hline Total & & 49 & 100.0 & & \\
\hline
\end{tabular}

The importance of password security is provided in Table 5. About $94 \%$ rated password protection as extremely or somewhat important.

Table 5

Question 3: How do you view the importance of password security?

\begin{tabular}{lcccc}
\hline & Frequency & Percent & Valid Percent & Cumulative Percent \\
\hline Extremely Important & 35 & 71.4 & 71.4 & 71.4 \\
Somewhat Important & 11 & 22.4 & 22.4 & 93.9 \\
Important & 2 & 4.1 & 4.1 & 98.0 \\
Not that Important & 1 & 2.0 & 2.0 & 100.0 \\
Total & 49 & 100.0 & 100.0 & \\
\hline
\end{tabular}


The number of passwords used in displayed in Table 6; fifty-five percent of the students use between three and five passwords.

Table 6

Question 4: Approximately how many passwords do you use?

\begin{tabular}{lcccc}
\hline & Frequency & Percent & Valid Percent & Cumulative Percent \\
\hline $1-2$ & 13 & 26.5 & 26.5 & 26.5 \\
$3-5$ & 27 & 55.1 & 55.1 & 81.6 \\
$6-10$ & 5 & 10.2 & 10.2 & 91.8 \\
$11-15$ & 2 & 4.1 & 4.1 & 95.9 \\
$15+$ & 2 & 4.1 & 4.1 & 100.0 \\
Total & 49 & 100.0 & 100.0 & \\
\hline
\end{tabular}

Tables 7 and 7a present the voluntary and involuntarily required changing of passwords, respectively. The majority of students (67\%) never voluntarily change their passwords; the majority (51\%) of participants is required to change their passwords on a monthly basis.

Table 7

Question 5: Approximately how often do you change your password(s) voluntarily?

\begin{tabular}{lcccc}
\hline & Frequency & Percent & Valid Percent & Cumulative Percent \\
\hline Missing & 2 & 4.1 & 4.1 & 4.1 \\
Every day & 1 & 2.0 & 2.0 & 6.1 \\
2-5 times a week & 2 & 4.1 & 4.1 & 10.2 \\
Once a month & 14 & 28.6 & 28.6 & 38.8 \\
Never & 30 & 61.2 & 61.2 & 100.0 \\
Total & 49 & 100.0 & 100.0 & \\
\hline
\end{tabular}

Table 7a

Question 6: How often do you change your password(s) because you are required to?

\begin{tabular}{lcccc}
\hline & Frequency & Percent & Valid Percent & Cumulative Percent \\
\hline Missing & 2 & 4.1 & 4.1 & 4.1 \\
Every day & 1 & 2.0 & 2.0 & 6.1 \\
Once a week & 1 & 2.0 & 2.0 & 8.2 \\
Once a month & 25 & 51.0 & 51.0 & 59.2 \\
Never & 20 & 40.8 & 40.8 & 100.0 \\
Total & 49 & 100.0 & 100.0 & \\
\hline
\end{tabular}

In Table 8, the level of difficulty in changing passwords is shown. The degree of difficulty in changing passwords was almost evenly divided between those who answered as difficult or worse and those that felt it was not difficult.

Table 8

Question 7:How difficult do you find it to change your passwords?

\begin{tabular}{lcccc}
\hline & Frequency & Percent & Valid Percent & Cumulative Percent \\
\hline Extremely difficult & 7 & 14.3 & 14.3 & 14.3 \\
Somewhat difficult & 13 & 26.5 & 26.5 & 40.8 \\
Difficult & 4 & 8.2 & 8.2 & 49.0 \\
Not that Difficult & 19 & 38.8 & 38.8 & 87.8 \\
Not Difficult & 6 & 12.2 & 12.2 & 100.0 \\
Total & 49 & 100.0 & 100.0 & \\
\hline
\end{tabular}

Familiarity with software that assists in creating, saving, and recalling password revealed that $85 \%$ did not know that software existed to facilitate working with passwords as displayed in Table 9. 
Table 9

Question 8: Are you familiar with any software that aids in creation, saving, and recalling your personal passwords?

\begin{tabular}{ccccc}
\hline & Frequency & Percent & Valid Percent & Cumulative Percent \\
\hline No & 42 & 85.7 & 85.7 & 85.7 \\
Yes & 7 & 14.3 & 14.3 & 100.0 \\
Total & 49 & 100.0 & 100.0 & \\
\hline
\end{tabular}

Approximately $57 \%$ of respondents as provided in Table 10 would be interested in software that helped in managing passwords.

Table 10

Question 10: Would you be interested in such a tool, if you aren't familiar with one?

\begin{tabular}{lcccc}
\hline & Frequency & Percent & Valid Percent & Cumulative Percent \\
\hline Missing & 3 & 6.1 & 6.1 & 6.1 \\
No & 18 & 36.7 & 36.7 & 42.9 \\
Yes & 28 & 57.1 & 57.1 & 100.0 \\
Total & 49 & 100.0 & 100.0 & \\
\hline
\end{tabular}

Table 11 displays the relative importance of password protection based on the type of device. In this table, extremely high importance was attributed to the desktop computer, iPad/tablet, laptop/netbook, cell phone and ereader as $46.7 \%, 28.6 \%, 61.2 \%, 46.9 \%$, and $6.1 \%$, respectively. Clearly the laptop/netbook was identified as the most critical device for password security.

Table 11

Question 11: Importance of Password Protection by Device Type: Desktop Computers

\begin{tabular}{llcccc}
\hline & & Frequency & Percent & Valid Percent & Cumulative Percent \\
\hline & Extremely important & 23 & 46.9 & 48.9 & 48.9 \\
& Somewhat important & 10 & 20.4 & 21.3 & 70.2 \\
& Important & 5 & 10.2 & 10.6 & 80.9 \\
& Not Important & 9 & 18.4 & 19.1 & 100.0 \\
& Total & 47 & 95.9 & 100.0 & \\
Missing & System & 2 & 4.1 & & \\
Total & & 49 & 100.0 & & \\
\hline
\end{tabular}

Question 12: Importance of Password Protection by Device Type: iPad/Tablet

\begin{tabular}{|c|c|c|c|c|c|}
\hline & & Frequency & Percent & Valid Percent & Cumulative Percent \\
\hline & Extremely Important & 14 & 28.6 & 30.4 & 30.4 \\
\hline & Somewhat Important & 12 & 24.5 & 26.1 & 56.5 \\
\hline & Important & 9 & 18.4 & 19.6 & 76.1 \\
\hline & Not Important & 11 & 22.4 & 23.9 & 100.0 \\
\hline & Total & 46 & 93.9 & 100.0 & \\
\hline Missing & System & 3 & 6.1 & & \\
\hline Total & & 49 & 100.0 & & \\
\hline
\end{tabular}

Question 13: Importance of Password Protection by Device Type: Laptop/Netbook

\begin{tabular}{llcccc}
\hline & & Frequency & Percent & Valid Percent & Cumulative Percent \\
\hline & Extremely Important & 30 & 61.2 & 62.5 & 62.5 \\
& Somewhat Important & 9 & 18.4 & 18.8 & 81.3 \\
& Important & 4 & 8.2 & 8.3 & 89.6 \\
& Not Important & 5 & 10.2 & 10.4 & 100.0 \\
& Total & 48 & 98.0 & 100.0 & \\
Missing & System & 1 & 2.0 & & \\
Total & & 49 & 100.0 & & \\
\hline
\end{tabular}


Table 11 (Continued)

Question 14: Importance of Password Protection by Device Type: Cell Phone

\begin{tabular}{llcccc}
\hline & & Frequency & Percent & Valid Percent & Cumulative Percent \\
\hline & Extremely Important & 23 & 46.9 & 48.9 & 48.9 \\
& Somewhat Important & 11 & 22.4 & 23.4 & 72.3 \\
& Important & 7 & 14.3 & 14.9 & 87.2 \\
& Not Important & 6 & 12.2 & 12.8 & 100.0 \\
& Total & 47 & 95.9 & 100.0 & \\
Missing & System & 2 & 4.1 & & \\
Total & & 49 & 100.0 & & \\
\hline
\end{tabular}

Question 15: Importance of Password Protection by Device Type: E-Reader

\begin{tabular}{|c|c|c|c|c|c|}
\hline & & Frequency & Percent & Valid Percent & Cumulative Percent \\
\hline & Extremely Important & 3 & 6.1 & 6.5 & 6.5 \\
\hline & Somewhat Important & 9 & 18.4 & 19.6 & 26.1 \\
\hline & Important & 11 & 22.4 & 23.9 & 50.0 \\
\hline & Not Important & 23 & 46.9 & 50.0 & 100.0 \\
\hline & Total & 46 & 93.9 & 100.0 & \\
\hline Missing & System & 3 & 6.1 & & \\
\hline Total & & 49 & 100.0 & & \\
\hline
\end{tabular}

\section{Discussion of the Relationships between Perception and Practice}

The next analysis connects student views (perceptions about password protection) with their behavior (practice). Contingency tables with chi-square analysis were used to investigate the relationship among the variables identified in Table 12. In this table each of the variable constructs are connected to the questions in the survey and defined in terms of how the categories were created. For example, the variable importance was developed from question three and has two categories: high and low; respondents who answered this question with choices (a) or (b) were classified as high importance and students who selected (c) or (d) were assigned to the low importance category. As a result of Table 12 the variables that will be investigated using contingency table analysis are sites visited, importance, usage, difficulty, and interest.

Table 12

Variables, Questions, and Categories

\begin{tabular}{lll}
\hline Variable: Description & Question & Categories \\
\hline Sites Visited: & $\# 1$ & Low (1): (a) 0-5 \\
Identifies web sites that require a password to visit & & Medium (2): (b) $6-10$ \\
& & High (3): (c) 11-15 \\
& & Very High (4): (d) more than 15 \\
Importance: & $\# 3$ & High (1): (a) Extremely Important \\
Identifies the importance of passwords & & High (1): (b) Somewhat Important \\
& & Low (0): (c) Not that Important \\
Usage: & Low (0): (d) Not Important at all \\
Identifies the number of passwords used & $\# 4$ & Low (1): (a) 1-2 \\
& & Medium (2): (b) 3-5 \\
Difficulty: & & High (3): (c) 6-10 \\
Identifies the difficulty in changing passwords & Very High (4): (d) 11 - 15 \\
& $\# 7$ & Difficult (1) (a) Extremely Difficult \\
Interest: & & Difficult (1): (b) Somewhat Difficult \\
Identifies interest in an automated password management tool & & Difficult (1): (c) Difficult \\
& & Not Difficult (0): (d) Not that Difficult \\
& & Not Difficult (0): (e) Not Difficult at all
\end{tabular}


Do students who view importance as a high concern have a strong interest in automated password tools? Figure 1 presents a bar graph of the frequency for the importance and interest variables. There was no significant association between importance and interest $\chi^{2}(1)=1.961, p=.161$. The Phi coefficient was -.206 which also indicates a weak association between these constructs.

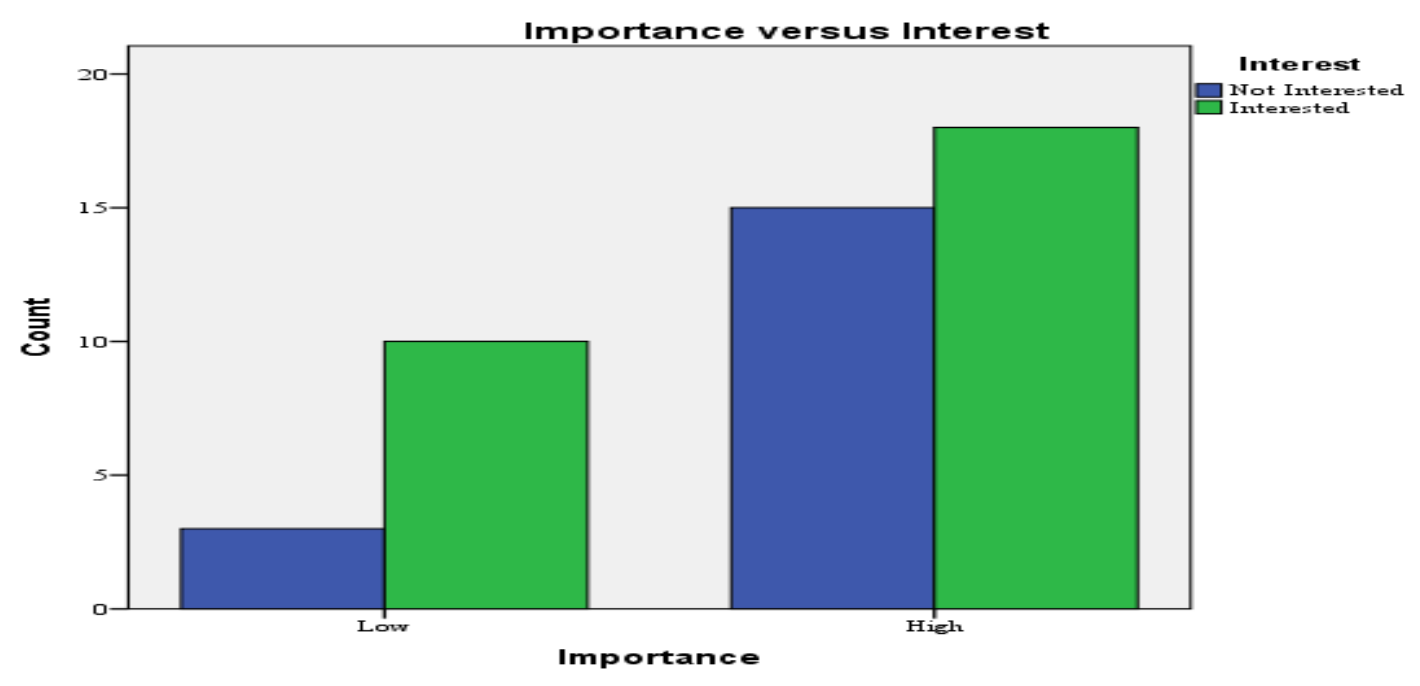

Figure 1

Do students who visit a larger number of sites more likely to use more passwords? Figure 2 displays the graph for the variables of sites visited and usage. There was a significant relationship at an alpha of .05 between sites visited and password usage $\chi^{2}(9)=28.964 p=.001$. The Phi coefficient was .769 which also indicates a strong positive association. The more sites visited the greater is their use of passwords.

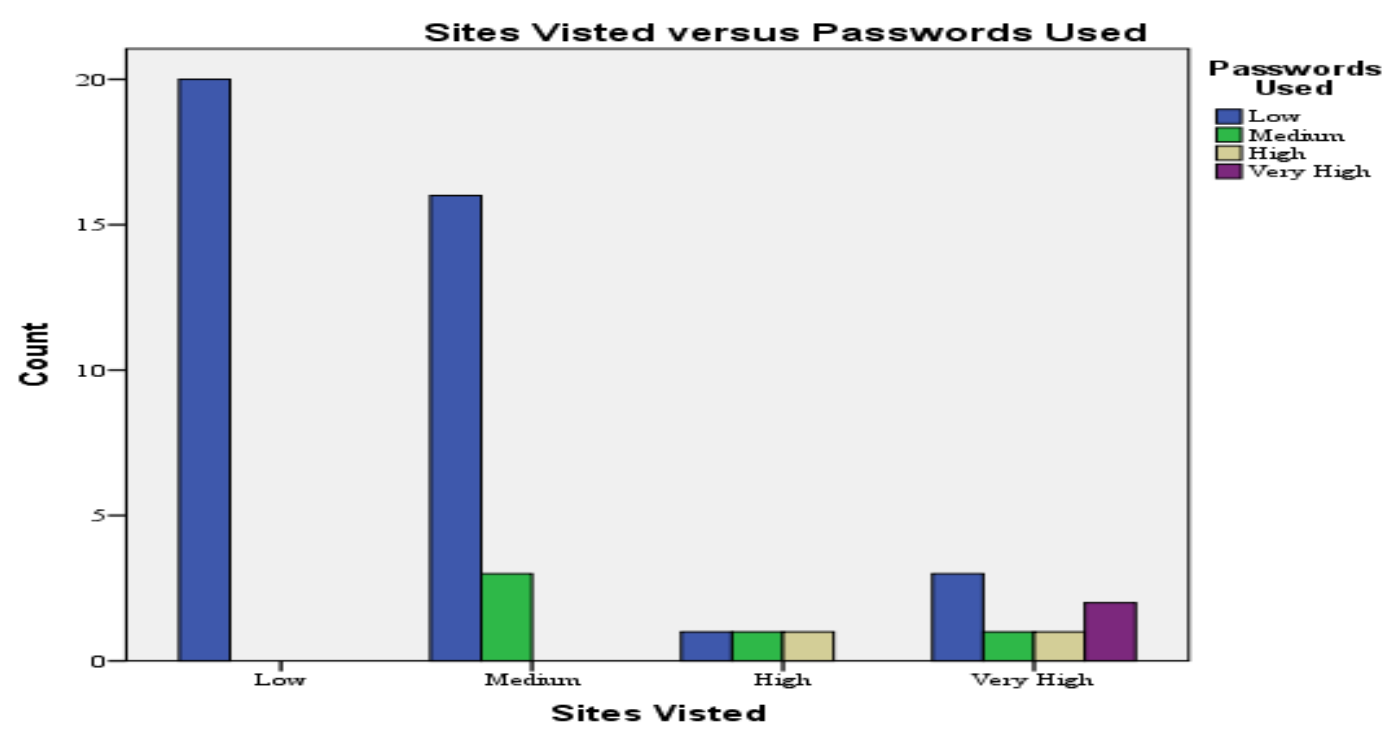

Figure 2 
Does the level of difficult in changing password support more interest in an automated solution for managing passwords? Figure 3 presents the relationship between difficulty and interest. There was a significant relationship at an alpha of .05 between difficulty and interest $\chi^{2}(1)=11.506 \mathrm{p}=.001$. The Phi coefficient was .5 which also suggests a positive association between difficulty and interest.

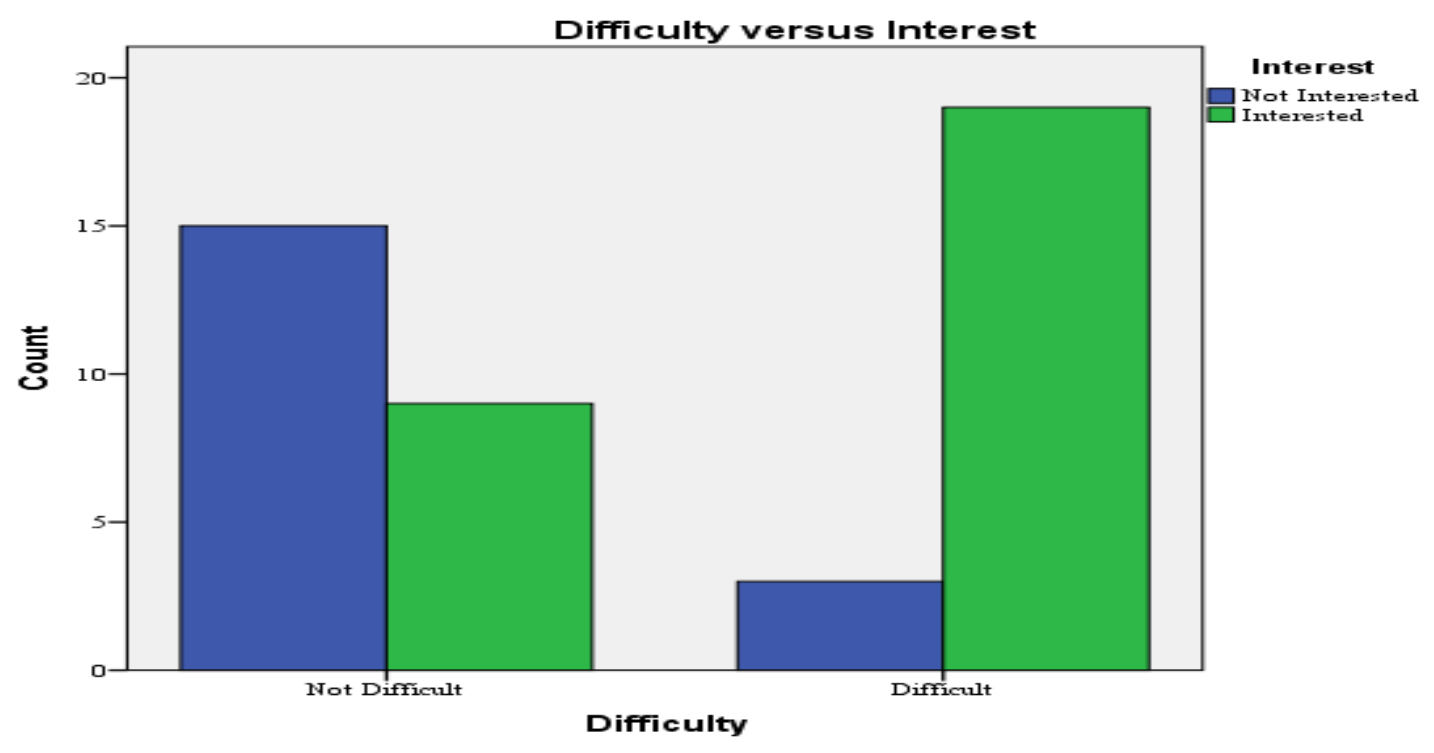

Figure 3

Are students who view passwords as important more inclined to use passwords more frequently? Figure 4 displays the relationship between importance and usage. There was no significant association between importance and usage at an alpha of $.05 \chi^{2}(3)=1.592, p=.661$. The Phi coefficient was .180 which also indicates a weak association between these variables. The number of sites visited that require passwords and the perception of the importance of password protection appear to be unrelated.

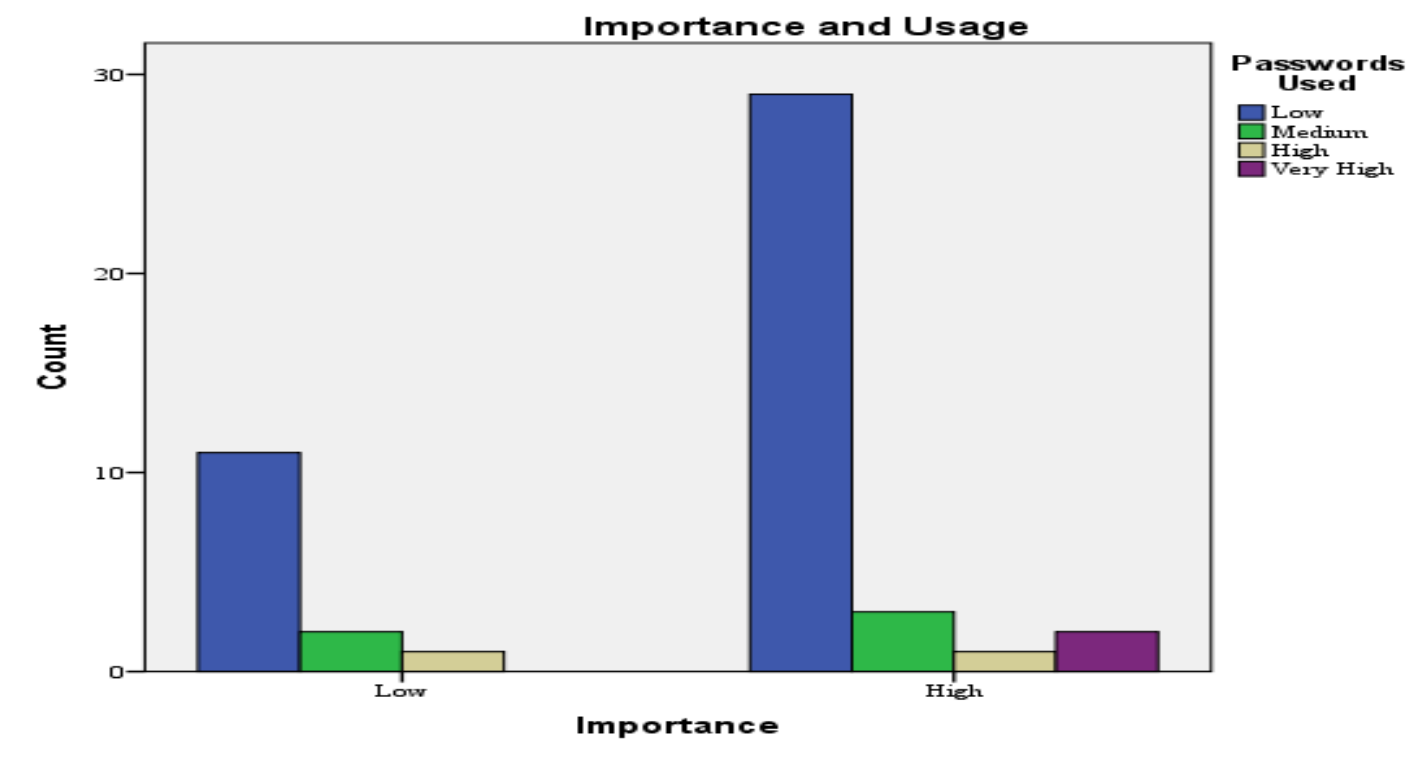

Figure 4 


\section{CONCLUSION}

This paper examined the perceptions and practices of students in password protection. A survey was administered to undergraduates to collect data about their views and behaviors in password protection. This research contributes to understanding some of the attitudes and habits of students in their use of passwords. Approximately 94\% of the respondents to the survey felt that password protection was important. The perception of the degree of trouble of changing password was almost evenly divided between a high level of difficult and a low level of difficulty among the students surveyed. The majority of students in the study (57\%) are interested in learning about a software tool to automate password management.

In terms of the relationships between the perceptions and the behaviors reported in the survey, it was found that there is a significant relationship between the number of sites requiring passwords and the use of passwords. No statistical association between the importance of passwords and their use. There was no significant relationship found between the importance of password protection and interest in a software tool to automate password management. On the other hand there was a significant relationship between the difficulty in changing passwords and interest in an automated tool. Additional research with larger samples is recommended to develop more complete exploratory models that would connect the perception of password protection with its associated behaviors.

\section{AUTHOR INFORMATION}

Dr. Cynthia Knott has been a member of the Marymount faculty since 2005. Dr. Knott teaches undergraduate and graduate courses in information systems, operations management, statistical analysis, and decision making. Dr. Knott holds an MBA and a Ph.D from The George Washington University in Washington, DC. Dr. Knott has presented her research internationally, including conferences in Chile, Turkey, Japan, and Switzerland. She has also been published in the Journal of the Operations Research Society, the Journal of the International Federation of Operational Research Societies (ITOR-IFORS), and the Journal of Applied Business and Economics. Her current research interests include quantitative methods and their application to education, business, and society. Specifically, Dr. Knott is investigating innovative ways to teach and engage students in operations research and statistical methods as well as in the area of encryption and portable data storage. She is also working in the area of health care, information technology, and marketing. She collaborates extensively with other Marymount faculty members and presents her research with these colleagues at professional conferences around the world. E-mail: cknott@marymount.edu. Corresponding author.

Dr. Gerard Steube has conducted research in a wide variety of areas including health, defense, and education. He has expertise in Information Technology and Management Science. He has participated in presentations on software complexity at major computer science conferences and conducted research that profiles computer hackers. In addition, he has provided consulting services for federal, state, and private organizations in developing information technology policies, software management plans, and outsourcing strategies. Dr. Steube provided statistical examination of Medicare and Medicaid data for the state of Maryland. He has worked on federal grants for investigating software complexity and networking and has developed software in C++, COBOL, FORTRAN, Perl, PHP, SQL, and Java. In industry he has held positions including the director of information technology, chief computer scientist, executive director of technology, director of software research, and research statistician. He was awarded the CCP (Certified Computer Professional) designation from the Institute for the Certification of Computer Professionals (ICCP) and is certified for Institutional Research Board work by the Collaborative Institutional Training Initiative. Dr. Steube is a member of MENSA and a certified MENSA test proctor; he has served as the editor for the MENSA International Journal. He serves as a reviewer and editorial board member for the Journal of Information Systems Education (JISE). Dr. Steube is a voting member in the American Psychological Association, the Mathematical Association of America, the Association for Computing Machinery, and the American Statistical Association. He is a published restoration photographer and a Web site designer. E-mail: gsteube @ marymount.edu 


\section{REFERENCES}

1. About.com. (2011). Polybius on the Roman military. Retrieved December 1, 2011, from http://ancienthistory.about.com/library/bl/bl_text_polybius6.htm

2. Howell, D. C. (2002). Statistical methods for psychology (5th ed.). Pacific Grove, CA: Duxbury/Thomson Learning.

3. Morris, R., \& Thompson, K. (1979). Password security: A case history. Retrieved December 1, 2011, from https://info.aiaa.org/tac/isg/SOFTC/Public\%20Documents/Technical\%20Working\%20Groups/Cyber\%20S ecurity/Password\%20Security\%20A\%20case\%20Study.pdf

4. Simon, S. (2005). What is a phi coefficient? Retrieved November 2, 2010, from http://www.childrensmercy.org/stats/definitions/phi.htm

5. The JNT Association. (2007). Using passwords. Retrieved December 1, 2011, from http://www.ja.net/documents/publications/factsheets/026-using-passwords.pdf 


\section{APPENDIX A}

\section{Survey Questions}

Please provide your responses to the following questions about using passwords to secure your data and information. Note: this is a completely voluntary survey.

1. Approximately how many web sites do you visit that require a password?
a. $0-5$
b. $6-10$
c. $11-15$
d. More than 15

2. Given the following classifications, approximately how many web sites of each type do you use that require passwords? Please insert a number for each category. You may use zero (0) to indicate that no passwords are required.
a. Personal Banking
b. Social Networking
c. Shopping
d. Gaming

3. How do you view the importance of password security?
a. Extremely Important
b. Somewhat Important
c. Important
d. Not that Important
e. Not Important at all

4. Approximately how many passwords do you use?
a. $1-2$
b. $3-5$
c. $6-10$
d. 11-15
e. More than 15

5. Approximately how often do you change your password(s) voluntarily?
a. Every day
b. 2-5 times a week
c. Once a week
d. Once a month
e. Never

6. How often do you change your password(s) because you are required to?
a. Every day
b. 2-5 times a week
c. Once a week
d. Once a month
e. Never

7. How difficult do you find it to change your passwords, given many sites requirements to include a capital letter, symbol etc...?
a. Extremely Difficult
b. Somewhat Difficult
c. Difficult
d. Not that Difficult
e. Not Difficult at all

8. Are you familiar with any software that aids in creation, saving, and recalling your personal passwords? $\mathrm{Y} \quad \mathrm{N}$

9. If you answered Yes to Question 8, what is the name of the software?

10. Would you be interested in such a tool, if you aren't familiar with one? Y
$\mathrm{N}$ 
Please rate each of the following devices listed in the table by circling your choice. How would you rate the importance of securing each of them with password protection?

(1-Extremely Important, 2-Somewhat Important, 3-Important, 4-Not Important)

Table 1: Electronic Devices

\begin{tabular}{|l|l|c|c|c|c|}
\hline & & $\begin{array}{c}\text { Extremely } \\
\text { Important }\end{array}$ & $\begin{array}{c}\text { Somewhat } \\
\text { Important }\end{array}$ & Important & Not Important \\
\hline 11 & Desktop Computer & 1 & 2 & 3 & 4 \\
\hline 12 & iPad/Tablet & 1 & 2 & 3 & 4 \\
\hline 13 & Laptop/Netbook & 1 & 2 & 3 & 4 \\
\hline 14 & Cell Phone & 1 & 2 & 3 & 4 \\
\hline 15 & E-Reader & 1 & 2 & 3 & 4 \\
\hline
\end{tabular}

